\title{
Diagnosis, treatment, and burden of illness among adults with attention-deficit/ hyperactivity disorder in Europe
}

This article was published in the following Dove Press journal:

Pragmatic and Observational Research

28 July 2014

Number of times this article has been viewed

\section{Stephen L Able' \\ Virginia Haynes' \\ Jihyung Hong ${ }^{2}$}

'Eli Lilly and Company, Indianapolis, IN, USA; ${ }^{2}$ Eli Lilly and Company,

Windlesham, UK
Correspondence: Stephen L Able

Tel +3I7 $27636 / 2$

$\mathrm{Fax}+3172771548$

Email able_stephen_|@lilly.com
Purpose: To quantitatively address the burden of attention-deficit/hyperactivity disorder (ADHD) in Europe (Germany, the UK, Sweden, Denmark, and the Netherlands), to describe adult experience leading to diagnosis and treatment of ADHD, and to compare those findings with results from the US.

Survey respondents and methods: Data were collected from an international web-based survey of adults from Europe and the US. Sociodemographics, comorbidities, work productivity/ activity impairments, and health care utilization of adults reporting an ADHD diagnosis $(n=431)$ and a similar number of adults without ADHD ( $n=449)$ were compared. Respondents' experiences with the diagnosis and treatment of ADHD and the perceived effects of the condition on psychosocial functioning were assessed. In addition, multivariate regression analyses were performed to compare the burden of ADHD between the two regions.

Results: Adults with ADHD in both regions were generally less likely to be married, employed, or rate their health as good/very good/excellent and were more likely to smoke, have experienced alcoholism, have other mental health conditions, have work productivity/activity impairments, and use health care resources. Although the specialties of health care professionals consulted prior to diagnosis were similar between the two regions, there was a notable difference in the length of time it took to receive a first ADHD diagnosis. Only 55\% of European respondents received a diagnosis within 6 months of their first physician consultation regarding their ADHD symptoms, compared to $90 \%$ in the US. The results of regression analyses confirmed a greater impact of ADHD on psychosocial functioning, work productivity impairments, and the total number of provider visits in Europe.

Conclusion: The results revealed a significant impact of ADHD on adults over a range of outcomes, including social, family, and work relationships, health-related work productivity impairment, and health care resource use, with a generally greater burden of illness among European study participants than those from the US.

Keywords: ADHD, adults, treatment, diagnosis, burden, Europe, US

\section{Introduction}

Attention-deficit/hyperactivity disorder (ADHD) is a neuropsychiatric disorder characterized by symptoms of inattention with or without evidence of impulsivity and hyperactivity. ${ }^{1}$ Historically, ADHD has been widely recognized and described as a condition affecting school-aged children, but it is now increasingly accepted as a valid diagnosis in adults as well. ${ }^{1,2}$ Several recent studies have shown that symptoms and impairments of childhood ADHD can persist into adulthood as either the full condition or in partial remission. ${ }^{3}$ Using a meta-analysis of ADHD follow-up studies, Faraone et $\mathrm{al}^{4}$ reported that up to $65 \%$ of children with ADHD continued to 
experience symptoms into adulthood. In addition, as part of the World Health Organization's World Mental Health Survey Initiative, Fayyad et $\mathrm{al}^{5}$ studied ADHD among adults aged 18-44 years in ten countries and reported a pooled prevalence of $3.4 \%$ (range $1.2 \%-7.3 \%$ ).

Most adults with ADHD predominantly exhibit problems with inattention, which manifest as forgetfulness, disorganization, and difficulty in planning, task completion, and time management. ${ }^{6,7}$ These symptoms can have a great impact on functioning in day-to-day life, including substantial impairments in both workplace and social environments. ${ }^{8-10}$ In addition, adults with ADHD have been shown to be at increased risk of antisocial and potentially harmful behavior, such as alcohol abuse, drug abuse, and criminal activity. ${ }^{9-12}$ Furthermore, they often have comorbid psychiatric conditions, such as depression, anxiety, and bipolar disorder. ${ }^{9-11,13}$

Not surprisingly, the economic impact of ADHD in adults places a significant burden on society, not only in direct medical costs associated with diagnosing and treating the disorder, but also through lost productivity and other indirect societal costs resulting from behavioral patterns associated with the condition. ${ }^{14}$ The size of this burden has been relatively well documented, at least within the US, in numerous studies conducted over the past 15 years. For example, a recent systematic review of 19 US studies reported the overall national annual incremental costs of ADHD to be in the range of \$143-\$266 billion (2010 US dollars), most of which were incurred by adults (\$105-\$194 billion). ${ }^{15}$ Workforce productivity costs in adults with ADHD were found to be the single largest contributor to the economic burden associated with the condition, amounting to \$87-\$138 billion and accounting for at least $70 \%-80 \%$ of the overall costs of ADHD in adults. Spillover costs borne by family members of individuals with ADHD were also found to be substantial (\$33-\$43 billion). Furthermore, the authors noted that the true societal costs of ADHD could be even greater than those reported, as additional components of total costs, such as ADHD-related substance abuse, traffic accidents, and encounters with the justice system, were omitted or not fully captured in the reviewed studies. ${ }^{15}$

The burden of ADHD in adults has been much less wellstudied quantitatively, in either monetary or nonmonetary terms. However, a recent qualitative study examined the experience of ADHD in an adult population and reported that adults with ADHD in five European countries (France, Germany, Italy, the Netherlands, and the UK), the US, and Canada shared similar narratives in the primary domains of functioning and well-being, suggesting that the factors contributing to the burden of illness are likely directionally similar, at least across the seven countries studied, and are not limited to the US alone. ${ }^{16}$

Despite evidence of the substantial personal and social burden of illness accompanying ADHD, it remains frequently underdiagnosed and undertreated in the US and Europe. Less than one in three adults with ADHD in the US has been diagnosed with ADHD, and far fewer in many European countries. ${ }^{10}$ Several factors can contribute to this shortcoming, including a lack of awareness of the impact and consequences of ADHD among many mental health care professionals, misunderstanding of the nature of the disorder, the use of poorly age-adjusted clinical criteria for addressing the symptoms of ADHD in adults, the frequent presence of comorbid conditions, and cultural stigma/expectations about the disorder. ${ }^{3,10}$

The primary purpose of this study was to analyze the results of a web-based survey designed to assess the burden of illness associated with ADHD in adults in five western and northern European countries. More specifically, measures of health and psychosocial functioning, impairments to work productivity, and health care resource utilization were compared across adults with and without ADHD in Germany, the UK, Sweden, Denmark, and the Netherlands. In addition, the experience of respondents leading to their initial diagnosis and current treatment for ADHD were investigated. Data for the US were also gathered to provide a frame of reference for assessing the results for Europe.

\section{Material and methods Data source and study design}

Data for this study were obtained through web-based surveys among adults in five European countries (Germany, the UK, Sweden, Denmark, and the Netherlands) as well as the US. The survey was designed and implemented in collaboration with Kantar Health (New York, NY, USA), ${ }^{17}$ a large international provider of health-related research services and consultation, and comprised two distinct parts. Part A was designed to gather information regarding demographics, health status and history, work productivity, and resource utilization of adults self-reporting with and without a diagnosis of ADHD. Data collection for Part A of this study was based on Kantar Health's National Health and Wellness Survey (NHWS) database. Part B was designed to gather additional information relevant only to respondents with ADHD identified in Part A, such as condition-specific diagnosis and treatment experience and perceptions of the impact of ADHD on factors related to quality of life. 


\section{Overview of the NHWS}

The NHWS database is populated with the results of an annually conducted web-based survey among samples of adults in 18 countries across Europe, Asia, and North and South America. Survey samples for conducting the NHWS are obtained from consumer panels managed by Kantar Health's sister company, Lightspeed Research (Warren, NJ, USA), recruited through a network of local research partners. Participants for these country-specific panels are identified through a combination of opt-in emails, e-newsletter campaigns, banner placements, and internal and external affiliate networks. All prospective members must register for panel participation by providing a unique email address, complete an in-depth demographic registration profile, and agree to be contacted for participation in multiple web-based surveys (no more than twelve per year). Panel participants must provide informed consent, and all regional studies using data gathered through their survey participation must be approved by the Essex Institutional Review Board (Lebanon, NJ, USA).

The NHWS survey instrument consists of an extensive set of questions designed to support health-related research projects worldwide, including information on demographic characteristics, risky health-related behavior, personal and family health histories, current health status, measures of work productivity and activity impairment, and health care resource utilization. From a prespecified list of 39 health conditions in the personal health history component of the survey, respondents were asked to indicate which they had experienced within the previous 12 months and, for each experienced, whether a diagnosis had been rendered by a physician. Responses to these questions provide the basis for the creation of condition-specific data sets for detailed health care analyses.

\section{Sample selection and data collection for Part A}

For countries targeted for inclusion in the current research that were also included in Kantar Health's 2012 NHWS (Germany, the UK, and the US), data was provided for a selected subset of the totality of variables contained in the NHWS database for 18-64 year olds reporting a diagnosis of ADHD. To ensure the number of interviews among ADHD respondents was large enough to support statistically meaningful analysis at the country-specific level (approximately 100 in each), a second version of the NHWS incorporating only the select subset of questions included in the authors' extract from the total NHWS database was developed. This short version of the NHWS was administered independently to additional survey sample provided by Lightspeed
Research from its customer panels for those geographies with insufficient NHWS data.

Similar data extracts for 100 adults from the population without ADHD for each of these three study countries were also obtained to provide a means of comparison with those with ADHD. Cohorts of adults without ADHD were designed to preserve the age and sex match with the country population characteristics used in generating the full NHWS database.

The short version of the NHWS survey was also administered to individuals self-reporting a diagnosis of ADHD and to adults without ADHD in the three study countries not included in the annual NHWS survey process (Denmark, Sweden, and the Netherlands). The short version of the NHWS was designed to take an average of 8-10 minutes to complete. Study participants from Denmark, Sweden, and the Netherlands were pooled to create northern European cohorts of respondents with ( $\mathrm{n}=130)$ and without $(\mathrm{n}=149)$ ADHD for Part A analysis. Respondents from the UK, Germany, and Northern Europe cohorts were pooled to create total European cohorts.

\section{Data collection for Part B}

Data for Part B were gathered by means of a survey designed for administration to individuals with ADHD regarding ADHD-specific issues not covered by the NHWS, such as diagnostic and treatment history and perceived effects of ADHD on health and psychosocial functioning related to quality of life. This survey, which was newly designed in collaboration with Kantar Health, was administered to patients with ADHD from October to December 2012, either as a re-contact study among 2012 NHWS respondents or simultaneously with the administration of the short version NHWS for those not included in the NHWS database. This custom survey was designed to take 12-15 minutes to complete and was approved by the Essex Institutional Review Board. All questionnaires utilized in this study were administered in the appropriate country-specific languages, with translations from English by professional translators.

\section{Variables included in survey instrument Comorbidities}

All participants were asked whether they had experienced any of the following conditions in the past 12 months and, if so, whether they had been diagnosed with the condition by a physician: 1) depression; 2) anxiety or generalized anxiety disorder; 3) obsessive compulsive disorder, panic disorder, phobias, or social anxiety disorder; and 4) sleep difficulties or insomnia. 


\section{Diagnosis and treatment of adults with ADHD}

The following were assessed to describe respondents' experiences leading to the diagnosis of and treatment for ADHD: 1) the specialties of health care providers consulted regarding ADHD symptoms prior to diagnosis; 2) the specialties of health care providers initially diagnosing ADHD; 3) the time to diagnosis following the first visit to a health care provider for consultation regarding ADHD symptoms; 4) conditions for which respondents received diagnoses prior to their initial ADHD diagnosis (alcoholism, autism, Asperger syndrome, other substance use/abuse, bipolar disorder, depression, anxiety-related disorder, schizophrenia, any learning disability, conduct disorder, and any other mental health conditions); 5) respondent evaluations of opinions on health care providers and services; 6) current use of ADHD medications; and 7) types of nonpharmacological treatments ever received for ADHD. For point 5) above, respondents were asked to indicate their level of agreement ("strongly agree", "somewhat agree", "neither agree nor disagree", "somewhat disagree", or "strongly disagree") with each of the following statements: "It took too long to get diagnosed with ADHD", "My primary care physician (PCP) is/was not knowledgeable about ADHD", "I had difficulty getting a referral to a specialist for ADHD", and "My PCP seems/ seemed hesitant to diagnose ADHD in adults". The proportions of respondents indicating they strongly or somewhat agreed with each statement were reported.

\section{Perceived impact of ADHD on health} and psychosocial functioning

Adults with ADHD were asked to rate their level of agreement or disagreement ("strongly agree", "somewhat agree", "neither agree nor disagree", "somewhat disagree", or "strongly disagree") with statements that ADHD had negatively impacted their overall physical health, overall mental health, ability to achieve success in their career/ work life, self-esteem, relationships with their child/children, relationships with spouse or significant other, relationships at work/with coworkers, relationships with other people, and ability to be a good parent. The proportions reporting some degree of agreement, as above, were reported.

\section{Work Productivity and Activity Impairment (WPAI)}

The WPAI questionnaire was used to measure impairments in both paid work and unpaid work for all participants. ${ }^{18}$ It is a six-item, well-validated instrument that consists of four metrics: absenteeism (the percentage of work time missed because of one's health in the past 7 days), presenteeism (the percentage of impairment experienced because of one's health while at work in the past 7 days), overall work productivity loss (the percentage of overall work impairment because of one's health in the past 7 days combining both absenteeism and presenteeism), and activity impairment (the percentage of impairment in daily activities because of one's health in the past 7 days). The validity of the instrument has been established in several disease states. ${ }^{19,20}$

\section{Health care resource utilization}

All participants were asked about their use of health care resources in the past 6 months. Resource utilization was considered in terms of the number of visits to health care providers, emergency room (ER) visits (yes/no), and hospital admissions (yes/no).

\section{Statistical analyses}

The study population consisted of 431 adults self-reporting as having received an ADHD diagnosis from a physician ( $n=100$ for Germany, $n=130$ for northern Europe, $n=101$ for the UK, and $n=100$ for the US), and 449 adults from respondents without a diagnosis of ADHD ( $\mathrm{n}=100$ for Germany, $n=149$ for northern Europe, $n=100$ for the UK, and $n=100$ for the US).

Sociodemographics, comorbidity profiles, work productivity impairments, and health care utilization of adults with and without ADHD were described and compared in each region/ country, using t-tests for continuous variables and chi-square tests for categorical variables. Respondents' experience with diagnosis of and treatment for ADHD, as well as perceived impacts of ADHD on health and psychosocial functioning, were also described and compared between adults with ADHD in Europe and the US, using t-tests and chi-square tests. In addition, multivariate regression analyses were used to compare the impact of ADHD on health and psychosocial functioning, work productivity and activity impairments, and health care resource use in Europe and the US, controlling for age, sex, marital status, 4-year college graduation, employment status, self-report of good/very good/excellent health, history of alcoholism, smoking status, and select comorbidities (depression, anxiety/generalized anxiety disorder, other anxiety disorders, and sleep difficulties/insomnia). The interaction between region and ADHD status was also taken into account when the outcomes were assessed for adults with and without ADHD. Linear regressions were carried out for continuous variables (ie, WPAI items and the total number of health care provider visits), and least squares (LS) means were estimated to test whether the differences in the LS means of the outcomes 
between European and US patients with ADHD were statistically significant. Logistic regressions were also used for binary outcomes (ie, perceived impacts of ADHD, ER visits, and hospital admissions). Perceived impacts of ADHD were assessed only for respondents with ADHD, and thus the odds ratio (OR) of having such negative impacts among Europeans with ADHD (compared with the US) were directly taken from the results of the models. For the other binary outcomes, LS mean differences in terms of OR were estimated to compare the impacts of ADHD among adults with ADHD in Europe and the US.

All test results were considered statistically significant at $P<0.05$. All statistical analyses were performed in SAS version 9.3 (SAS Institute Inc., Cary, NC, USA).

\section{Results}

\section{Sociodemographic characteristics and comorbidity profiles}

Sociodemographic characteristics of adults with and without ADHD are described for each country/region in Table 1. Adults with ADHD were generally younger than those without ADHD, who were age-and sex-matched to their country populations. In Europe, the mean age of adults with ADHD was 35.7 years (standard deviation [SD] 10.9 years), whereas that of adults without ADHD was 41.4 years (SD 13.1 years). In the US, the mean age of adults with ADHD (40.7 years [SD 12.5 years]) was similar to that of those without ADHD (41.4 years [SD 13.9 years]). Although the proportion of men with ADHD (50.5\%) was similar to that of those without in Europe (50.0\% versus 51.0\%), the proportion with ADHD was much lower than that of those without in the US (33.0\% versus $50.0 \%)$.

Compared to respondents without ADHD, those with ADHD were generally less likely to be married $(45.6 \%$ versus $66.5 \%$, respectively, in Europe and $40.0 \%$ versus $47.0 \%$, respectively, in the US) and be employed $(55.3 \%$ versus $64.2 \%$, respectively, in Europe and $62.0 \%$ versus $78.0 \%$, respectively, in the US). They were also less likely to rate their health as good/very good/excellent (54.4\% versus $76.8 \%$, respectively, in Europe and $74.0 \%$ versus $91.0 \%$,

Table I Sociodemographic characteristics of adults with and without ADHD in Europe and the US

\begin{tabular}{|c|c|c|c|c|c|}
\hline & $\begin{array}{l}\text { Germany } \\
\left(n_{1}=100 ; n_{2}=100\right)\end{array}$ & $\begin{array}{l}\text { Northern Europe } \\
\left(n_{1}=130 ; n_{2}=149\right)\end{array}$ & $\begin{array}{l}\text { UK } \\
\left(n_{1}=101 ; n_{2}=100\right)\end{array}$ & $\begin{array}{l}\text { Europe } \\
\left(n_{1}=331 ; n_{2}=349\right)\end{array}$ & $\begin{array}{l}\text { US } \\
\left(n_{1}=100 ; n_{2}=100\right)\end{array}$ \\
\hline \multicolumn{6}{|l|}{ Age, mean (SD) } \\
\hline ADHD & $38.7(10.9)$ & $35.3(11.5)^{*}$ & $33.3(9.5)^{*}$ & $35.7(10.9)^{*}$ & $40.7(12.5)$ \\
\hline Non-ADHD & $41.8(12.3)$ & $41.8(13.5)$ & $40.4(13.5)$ & $4 I .4(13.1)$ & $41.4(13.9)$ \\
\hline \multicolumn{6}{|c|}{ Age at the first ADHD diagnosis, mean (SD) } \\
\hline ADHD & $9.23(9.31)$ & $6.78(7.27)$ & $8.95(7.90)$ & $8.18(8.18)$ & $12.34(9.56)$ \\
\hline Non-ADHD & - & - & - & - & - \\
\hline \multicolumn{6}{|l|}{ Male, \% } \\
\hline ADHD & 49.0 & 46.9 & 56.4 & 50.5 & $33.0 *$ \\
\hline Non-ADHD & 51.0 & 51.7 & 50.0 & 51.0 & 50.0 \\
\hline \multicolumn{6}{|c|}{ Married/partner, \% } \\
\hline ADHD & $44.0 *$ & $42.3^{*}$ & $51.5^{*}$ & $45.6 *$ & 40.0 \\
\hline Non-ADHD & 65.0 & 65.8 & 69.0 & 66.5 & 47.0 \\
\hline \multicolumn{6}{|c|}{ College education, \% } \\
\hline ADHD & 26.0 & 36.9 & 51.5 & 38.1 & 52.0 \\
\hline Non-ADHD & 21.0 & 39.6 & 41.0 & 34.7 & 52.0 \\
\hline \multicolumn{6}{|l|}{ Employed, \% } \\
\hline ADHD & 55.0 & $42.3 *$ & 72.3 & $55.3^{*}$ & $62.0 *$ \\
\hline Non-ADHD & 64.0 & 66.4 & 61.0 & 64.2 & 78.0 \\
\hline \multicolumn{6}{|c|}{ Self-reported good health, \% } \\
\hline ADHD & $48.0 *$ & $48.5^{*}$ & 68.3 & $54.4^{*}$ & $74.0 *$ \\
\hline Non-ADHD & 77.0 & 76.5 & 77.0 & 76.8 & 91.0 \\
\hline \multicolumn{6}{|c|}{ Current smoker, \% } \\
\hline ADHD & 47.0 & $45.4^{*}$ & $53.5^{*}$ & $48.3^{*}$ & $24.0 *$ \\
\hline Non-ADHD & 38.0 & 25.5 & 24.0 & 28.7 & 13.0 \\
\hline \multicolumn{6}{|c|}{ Ever alcoholism, \% } \\
\hline ADHD & $22.0 *$ & $13.9 *$ & $24.8^{*}$ & $19.6 *$ & 7.0 \\
\hline Non-ADHD & 8.0 & 2.7 & 4.0 & 4.6 & 4.0 \\
\hline
\end{tabular}

Notes: *Significant differences between ADHD and non-ADHD respondents with and without ADHD in each country/region $(P<0.05)$. $\mathrm{n}_{1}$ and $\mathrm{n}_{2}$ represent the sample sizes of adults with and without ADHD, respectively, in each country.

Abbreviations: ADHD, attention-deficit/hyperactivity disorder; SD, standard deviation. 
respectively, in the US), more likely to smoke (48.3\% versus $28.7 \%$, respectively, in Europe and $24.0 \%$ versus $13.0 \%$, respectively, in the US) and have experienced alcoholism (19.6\% versus 4.6\%, respectively, in Europe and 7.0\% versus $4.0 \%$, respectively, in the US). However, no difference was found in the proportion of 4-year college graduation between those with and without ADHD across the countries.

In addition, adults with ADHD were more likely than those without to report the presence of (diagnosed) comorbid mental health conditions (eg, depression, anxiety/ generalized anxiety disorder, other anxiety disorders, and sleep difficulties/insomnia) experienced in the past 12 months (Figure 1). Approximately three-quarters of respondents with ADHD in both Europe (71.0\%) and the US (74.0\%) reported having at least one of the listed comorbidities; these rates were about three times higher than those without ADHD (24.6\% in Europe and 25.0\% in the US). On average, depression was the most commonly reported comorbidity among those with ADHD in both regions (47.1\% in Europe and $51.0 \%$ in the US), whereas other anxiety disorders (eg, obsessive-compulsive disorder, panic disorder, or social anxiety disorder) were the least commonly (though still frequently) reported (35.1\% in Europe and 34.0\% in the US).

\section{Respondent experience with diagnosis and treatment of ADHD}

In Europe and the US, the most common types of health care professionals with whom adults with ADHD consulted prior to receipt of their initial ADHD diagnosis were psychiatrists, closely followed by PCPs and psychologists (Table 2). A total of $54.7 \%$ of adults with ADHD in Europe and $50.0 \%$ in the US discussed their symptoms with psychiatrists before receiving a diagnosis of ADHD. Psychiatrists were also the most common type of health care professionals to make the first diagnosis of ADHD across the countries $(43.3 \%$ of respondents in Europe and $45.0 \%$ in the US). The exception was the UK, where $41.6 \%$ of adults with ADHD were initially diagnosed by

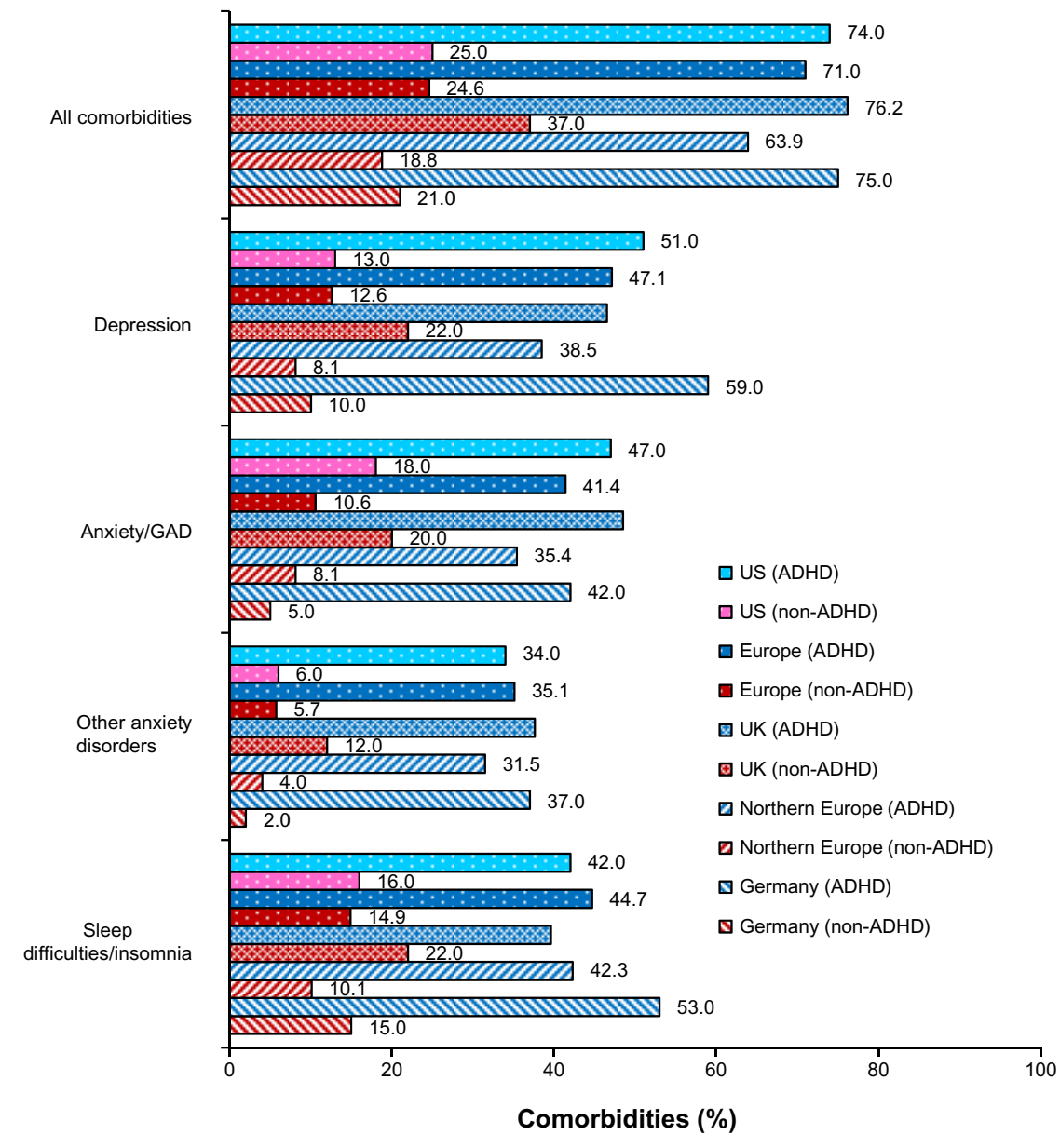

Figure I Self-reported comorbidities experienced within the past 12 months among adults with and without ADHD in Europe and the US. Note: The differences between adults with and without ADHD for each comorbidity in each country were significant $(P<0.01)$.

Abbreviations: ADHD, attention-deficit/hyperactivity disorder; GAD, Generalized Anxiety Disorder. 
Table 2 Diagnosis history of adults with ADHD in Europe and the US

\begin{tabular}{|c|c|c|c|c|c|}
\hline & $\begin{array}{l}\text { Germany } \\
(n=100), \%\end{array}$ & $\begin{array}{l}\text { Northern Europe } \\
(n=\mid 30), \%\end{array}$ & $\begin{array}{l}\text { UK } \\
(n=\mid 0 I), \%\end{array}$ & $\begin{array}{l}\text { Europe } \\
(n=331), \%\end{array}$ & $\begin{array}{l}\text { US } \\
(n=100), \%\end{array}$ \\
\hline \multicolumn{6}{|l|}{ Prior to diagnosis, consulted with } \\
\hline PCP & 49.0 & 48.5 & 63.4 & 53.2 & 42.0 \\
\hline Psychiatrist & 54.0 & 62.3 & 45.5 & 54.7 & 50.0 \\
\hline Psychologist & 43.0 & 53.9 & 33.7 & 44.4 & 35.0 \\
\hline Pediatrician & 10.0 & 8.5 & 8.9 & 9.1 & 8.0 \\
\hline \multicolumn{6}{|l|}{ First diagnosed by ${ }^{\mathrm{a}}$} \\
\hline PCP & 19.0 & 17.1 & 41.6 & 25.2 & 29.0 \\
\hline Psychiatrist & 51.0 & 50.4 & 26.7 & 43.3 & 45.0 \\
\hline Psychologist/therapist & 21.0 & 23.3 & 10.9 & 18.8 & 20.0 \\
\hline Pediatrician & 6.0 & 3.9 & 4.0 & 4.6 & 3.0 \\
\hline \multicolumn{6}{|l|}{ Time to first diagnosis ${ }^{\mathrm{a}}$} \\
\hline At first visit & 28.6 & 16.2 & 10.8 & $18.6^{*}$ & 42.1 \\
\hline Within 6 months (but not at first visit) & 33.0 & 38.5 & 36.1 & $36.1^{*}$ & 47.7 \\
\hline \multicolumn{6}{|l|}{ Diagnoses prior to initial ADHD diagnosis } \\
\hline Depression & 58.0 & 46.9 & 45.5 & 49.9 & 50.0 \\
\hline Anxiety & 43.0 & 22.3 & 33.7 & 32.0 & 34.0 \\
\hline Alcoholism & 15.0 & 7.7 & 11.9 & 11.2 & 7.0 \\
\hline Other substance abuse & 11.0 & 13.1 & 7.9 & 10.9 & 11.0 \\
\hline Conduct disorder & 36.0 & 20.0 & 6.9 & $20.9 *$ & 5.0 \\
\hline Learning disability & 26.0 & 15.4 & 15.8 & 18.7 & 17.0 \\
\hline Bipolar disorder & 9.0 & 9.2 & 11.9 & 10.0 & 10.0 \\
\hline Schizophrenia & 4.0 & 2.3 & 5.0 & 3.6 & 1.0 \\
\hline Autism & 5.0 & 10.8 & 13.9 & $10.0 *$ & 1.0 \\
\hline Asperger syndrome & 6.0 & 7.7 & 15.8 & $9.7^{*}$ & 1.0 \\
\hline Any other mental health conditions & 11.0 & 13.1 & 7.9 & 10.9 & 7.0 \\
\hline \multicolumn{6}{|l|}{ Patient experience with ADHD diagnosis } \\
\hline Took too long to get ADHD diagnosis & 62.8 & 46.8 & 46.7 & $51.6^{*}$ & 39.0 \\
\hline PCP not knowledgeable about ADHD & 47.8 & 30.8 & 29.2 & 35.7 & 40.5 \\
\hline Had difficulty getting referrals & 34.6 & 27.0 & 40.5 & 33.2 & 22.4 \\
\hline PCP hesitant to diagnosis ADHD & 46.6 & 35.0 & 39.8 & $40.2^{*}$ & 25.8 \\
\hline
\end{tabular}

Notes: *Significant differences between respondents with and without ADHD in Europe and the US $(P<0.05)$; a test for the difference between Europe and the US was performed for the variable itself, not for each category of the variable.

Abbreviations: ADHD, attention-deficit/hyperactivity disorder; PCP, primary care physician.

a PCP compared with approximately one-quarter $(26.7 \%)$ by psychiatrists.

Although proportions of each health care professional consulted were relatively similar between European and US ADHD respondents, there was a great discrepancy in time to first diagnosis between the two regions. Ninety percent of adults with ADHD in the US received a diagnosis within 6 months of their first visit to a health care professional regarding their ADHD symptoms, a significantly higher percentage than that reported in Europe (54.7\%; range 46.9\% in the UK to $61.6 \%$ in Germany). More than half of respondents with ADHD in Europe (51.6\%) agreed that it took too long to get an ADHD diagnosis, while $40.2 \%$ agreed that their PCP seemed hesitant to diagnose ADHD in adults. Both of these proportions were significantly higher than in the US (39.0\% and $25.8 \%$, respectively). Notably, across Europe, these rates were highest in Germany $(62.8 \%$ and $46.6 \%$, respectively). Although not significantly different, a higher proportion of adults with ADHD in Europe (33.2\%) than the US (22.4\%) also agreed that they had difficulty getting a referral to a specialist for ADHD. Nevertheless, equally high proportions of respondents with ADHD in Europe $(35.7 \%)$ and the US (40.5\%) felt that their PCPs were not knowledgeable about ADHD.

Table 2 also shows the mental health conditions which respondents were asked to indicate whether they had been diagnosed prior to receiving their initial diagnosis for ADHD. Depression was the most commonly reported pre-ADHD diagnosis, followed by anxiety, both in Europe and the US. Half of all respondents diagnosed with ADHD were previously diagnosed with depression, and approximately one in three with anxiety in each region $(32.0 \%$ in Europe and $34.0 \%$ in the US). In general, the frequencies of previous diagnoses were fairly similar between European and US respondents, except for autism, Asperger syndrome, and conduct disorder. Only $1.0 \%$ each in the US was previously 
diagnosed with autism or Asperger syndrome, respectively, whereas in Europe, $10.0 \%$ and $9.7 \%$ were diagnosed with these conditions. Similarly, the percentage of respondents who were previously diagnosed with conduct disorder in Europe (20.9\%) was approximately four times greater than that in the US $(5.0 \%)$, mostly attributable to relatively high rates of conduct disorder in Germany (36.0\%) and Northern Europe (20.0\%).

Pharmacological and nonpharmacological treatments for ADHD in adults in each country/region are presented in Table 3. A similar proportion of respondents in Europe $(58.6 \%)$ and the US $(57.0 \%)$ were being treated with at least one ADHD medication at the time they were surveyed. Methylphenidate was the most commonly prescribed medication in Europe (42.9\%, compared to $10.0 \%$ in the US) whereas amphetamine was the medication most commonly prescribed in the US $(31.0 \%$, compared with $9.4 \%$ in Europe). The use of nonstimulants was relatively low in both regions. Approximately $15 \%$ of respondents in Europe were prescribed nonstimulants $(5.4 \%$ for atomoxetine, $8.8 \%$ for clonidine, and $1.2 \%$ for guanfacine). Atomoxetine was the only nonstimulant prescribed in the US (11.0\%). Notably, more respondents in Europe (12.1\%), particularly in the UK $(17.8 \%)$, indicated they were taking at least two medications than in the US (3.0\%). In addition, a higher percentage of respondents in Europe (67.7\%) reported having ever received nonpharmacological treatments than those in the US (54.0\%). Although counseling was the most common type of nonpharmacological treatment in both regions (37.8\% in Europe and $40.0 \%$ in the US), significant differences between the two were found for cognitive behavioral therapy $(33.2 \%$ in Europe and $15.0 \%$ in the US) and diet supplements $(19.3 \%$ and $10.0 \%$, respectively).

\section{Impact of ADHD on psychosocial functioning, work productivity, and health care resource use}

Tables 4-6 show the negative impact of ADHD on health and psychosocial functioning, work productivity/activity, and health care resource use in Europe and the US. Table 4 describes the proportions of respondents who agreed that ADHD had a negative impact on various aspects of their health and psychosocial functioning. More than half of the respondents in Europe reported that ADHD negatively impacted their health, career success, self-esteem, and various personal and/or social relationships. For example, $64.4 \%$ of respondents in Europe believed that ADHD negatively impacted their career success. An equally high proportion $(68.3 \%)$ also reported a negative impact of ADHD on their self-esteem. The rates were highest in Germany, with 73.0\% for each. Although a similar pattern was observed in the US, the proportions were generally lower, suggesting greater impacts of ADHD in Europe (and Germany in particular) than in the US. This was also confirmed by regression analyses that controlled for respondent characteristics in Europe and the US. Compared with adults with ADHD in the US, those in Europe were more likely to report the negative impact of ADHD on overall physical health $(\mathrm{OR}=2.78 ; P<0.001)$, overall mental health $(\mathrm{OR}=1.77 ; P=0.033)$, relationships with spouse and significant other $(\mathrm{OR}=1.85 ; P=0.036)$,

Table 3 Pharmacological and nonpharmacological treatments for adults with ADHD in Europe and the US

\begin{tabular}{|c|c|c|c|c|c|}
\hline & $\begin{array}{l}\text { Germany } \\
(n=100), \%\end{array}$ & $\begin{array}{l}\text { Northern Europe } \\
(n=130), \%\end{array}$ & $\begin{array}{l}\text { UK } \\
(n=\mid 0 I), \%\end{array}$ & $\begin{array}{l}\text { Europe } \\
(n=331), \%\end{array}$ & $\begin{array}{l}\text { US } \\
(n=100), \%\end{array}$ \\
\hline Currently treated with ADHD medication ${ }^{\mathrm{a}}$ & 54.0 & 62.3 & 58.4 & 58.6 & 57.0 \\
\hline Methylphenidate & 40.0 & 50.8 & 35.6 & $42.9 *$ & 10.0 \\
\hline Amphetamine & 5.0 & 4.6 & 19.8 & $9.4^{*}$ & 31.0 \\
\hline Atomoxetine & 6.0 & 3.9 & 6.9 & 5.4 & I I.0 \\
\hline Clonidine & 9.0 & 3.1 & 15.8 & $8.8^{*}$ & 0.0 \\
\hline Guanfacine & 3.0 & 0.0 & 1.0 & 1.2 & 0 \\
\hline Other & 8.0 & 6.9 & 3.0 & 6.0 & 8.0 \\
\hline Combination & 13.0 & 6.9 & 17.8 & $12 . I^{*}$ & 3.0 \\
\hline Ever received nonpharmacological Tx & 72.0 & 59.2 & 74.3 & $67.7^{*}$ & 54.0 \\
\hline Counseling & 50.0 & 26.9 & 39.6 & 37.8 & 40.0 \\
\hline $\mathrm{CBT}$ & 34.0 & 32.3 & 33.7 & $33.2^{*}$ & 15.0 \\
\hline Mediation/breathing exercise & 28.0 & 16.9 & 15.8 & 19.9 & 21.0 \\
\hline Diet/supplements & 20.0 & 12.3 & 27.7 & $19.3^{*}$ & 10.0 \\
\hline Biofeedback, neurofeedback, or QEEG training & 3.0 & 3.9 & 5.0 & 3.9 & 7.0 \\
\hline Interactive metronome training & 8.0 & 3.9 & 12.9 & 7.9 & 3.0 \\
\hline
\end{tabular}

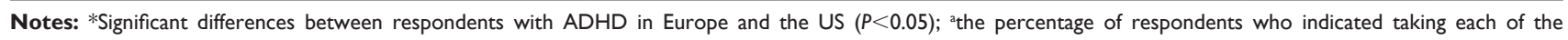
medications listed (multiple choice allowed).

Abbreviations: ADHD, attention-deficit/hyperactivity disorder; CBT, cognitive behavioral therapy; QEEG, quantitative electroencephalogram; Tx, treatment. 
Table 4 Self-reported negative impact of ADHD on health and psychosocial functioning among adults with ADHD in Europe and the US

\begin{tabular}{|c|c|c|c|c|c|c|c|}
\hline & \multirow[t]{2}{*}{$\begin{array}{l}\text { Germany } \\
(n=100), \%\end{array}$} & \multirow[t]{2}{*}{$\begin{array}{l}\text { Northern Europe } \\
(n=\mid 30), \%\end{array}$} & \multirow[t]{2}{*}{$\begin{array}{l}\text { UK } \\
(n=\mid 0 I), \%\end{array}$} & \multirow[t]{2}{*}{$\begin{array}{l}\text { Europe } \\
(n=331), \%\end{array}$} & \multirow[t]{2}{*}{$\begin{array}{l}\text { US } \\
(n=100), \%\end{array}$} & \multicolumn{2}{|c|}{$\begin{array}{l}\text { Europe vs US } \\
(\text { (ADHD) }\end{array}$} \\
\hline & & & & & & OR & $P$-value \\
\hline \multicolumn{8}{|l|}{ Negatively impacted on } \\
\hline Overall physical health & 65.0 & 46.2 & 45.5 & 51.7 & 27.0 & 2.78 & $<0.001$ \\
\hline Overall mental health & 73.0 & 66.9 & 61.4 & 67.1 & 54.0 & 1.77 & 0.033 \\
\hline Career success & 73.0 & 63.9 & 56.4 & 64.4 & 62.0 & 1.08 & 0.787 \\
\hline Self-esteem & 73.0 & 65.4 & 67.3 & 68.3 & 62.0 & 1.24 & 0.428 \\
\hline Relationship with children & 53.0 & 49.4 & 51.4 & 51.1 & 32.2 & 1.85 & 0.076 \\
\hline Relationship with significant others & 70.6 & 58.9 & 61.4 & 63.2 & 44.3 & 1.85 & 0.036 \\
\hline Relationship with co-workers & 61.7 & 59.3 & 63.3 & 61.3 & 42.1 & 1.74 & 0.049 \\
\hline Relationship with all others & 72.0 & 62.3 & 65.4 & 66.2 & 49.0 & 2.05 & 0.006 \\
\hline Ability to be a good parent & 44.9 & 45.9 & 44.9 & 45.3 & 37.7 & 1.27 & 0.476 \\
\hline
\end{tabular}

Notes: a ORs are of those reporting negative impacts of ADHD among adults with ADHD in Europe compared with their US counterparts, controlling for sociodemographics and comorbidity variables. OR $>$ I indicates greater odds of reporting negative impacts of ADHD among adults with ADHD in Europe.

Abbreviations: ADHD, attention-deficit/hyperactivity disorder; OR, odds ratio; SD, standard deviation; vs, versus.

Table 5 Level of work productivity/activity impairment (during the past week) of adults with and without ADHD in Europe and the US

\begin{tabular}{|c|c|c|c|c|c|c|c|}
\hline & \multirow{2}{*}{$\begin{array}{l}\text { Germany } \\
\left(n_{1}=100 ; n_{2}=100\right), \\
\text { Mean }(S D)\end{array}$} & \multirow{2}{*}{$\begin{array}{l}\text { Northern Europe } \\
\left(n_{1}=130 ; n_{2}=149\right), \\
\text { Mean (SD) }\end{array}$} & \multirow{2}{*}{$\begin{array}{l}\text { UK } \\
\left(n_{1}=101 ; n_{2}=100\right), \\
\text { Mean (SD) }\end{array}$} & \multirow{2}{*}{$\begin{array}{l}\text { Europe } \\
\left(n_{1}=331 ; n_{2}=349\right), \\
\text { Mean (SD) }\end{array}$} & \multirow{2}{*}{$\begin{array}{l}\text { US } \\
\left(n_{1}=100 ; n_{2}=100\right), \\
\text { Mean (SD) }\end{array}$} & \multicolumn{2}{|c|}{$\begin{array}{l}\text { Europe vs US } \\
\text { (ADHD) }^{\mathrm{a}}\end{array}$} \\
\hline & & & & & & Diff & $P$-value \\
\hline \multicolumn{8}{|l|}{ Absenteeism } \\
\hline ADHD & $19.5(28.2)^{*}$ & I3.I $(22.1)^{*}$ & $24.0(26.4)^{*}$ & $19.4(26.1)^{*}$ & $8.0(20.5)$ & 10.29 & 0.006 \\
\hline Non-ADHD & $6.3(21.4)$ & $3.1(13.2)$ & $6.3(21.6)$ & $4.9(18.3)$ & $2.5(9.8)$ & - & - \\
\hline \multicolumn{8}{|l|}{ Presenteeism } \\
\hline ADHD & $45.0(29.6)^{*}$ & $38.7(26.5)^{*}$ & $52.1(27.7)^{*}$ & $45.8(28.3)^{*}$ & $28.0(27.1)^{*}$ & 12.72 & 0.003 \\
\hline Non-ADHD & $15.9(22.3)$ & I6.I (23.2) & $19.6(23.6)$ & $17.0(23.0)$ & $12.8(24.3)$ & - & - \\
\hline \multicolumn{8}{|c|}{ Overall work impairment } \\
\hline ADHD & $52.8(32.8)^{*}$ & $46.4(28.4)^{*}$ & $60.8(30.4)^{*}$ & $54.0(31.1)^{*}$ & $32.2(30.4)^{*}$ & 17.42 & $<0.001$ \\
\hline Non-ADHD & $19.7(28.2)$ & I8.4 (25.8) & $24.4(29.0)$ & $20.4(27.4)$ & $13.9(25.2)$ & - & - \\
\hline \multicolumn{8}{|c|}{ Activity impairment } \\
\hline ADHD & $56.6(25.9)^{*}$ & $50.6(26.4)^{*}$ & $55.5(27.0)^{*}$ & $53.9(26.5)^{*}$ & $41.9(31.8)^{*}$ & 4.82 & 0.356 \\
\hline Non-ADHD & $29.4(30.8)$ & $24.5(27.5)$ & $31.1(33.0)$ & $27.8(30.2)$ & I7.0 (26.0) & - & - \\
\hline
\end{tabular}

Notes: *Significant differences between adults with and without ADHD in each country/region $(P<0.05)$; ${ }^{\text {the }}$ figures above present the differences in the least squares means of the outcomes between respondents with and without ADHD in Europe and the US, controlling for the interaction between ADHD status and region and for sociodemographics and comorbidity variables. A difference of more than zero indicates a higher level of work productivity/activity impairments among adults with ADHD in Europe. $n_{1}$ and $n_{2}$ represent the sample size of adults with and without ADHD, respectively, in each country.

Abbreviations: ADHD, attention-deficit/hyperactivity disorder; Diff, difference; SD, standard deviation; vs, versus.

Table 6 Health care resource utilization (in the past 6 months) of adults with and without ADHD in Europe and the US

\begin{tabular}{|c|c|c|c|c|c|c|c|}
\hline & \multirow[t]{2}{*}{$\begin{array}{l}\text { Germany } \\
\left(n_{1}=100 ; n_{2}=100\right)\end{array}$} & \multirow[t]{2}{*}{$\begin{array}{l}\text { Northern Europe } \\
\left(n_{1}=130 ; n_{2}=149\right)\end{array}$} & \multirow[t]{2}{*}{$\begin{array}{l}\text { UK } \\
\left(n_{1}=101 ; n_{2}=100\right)\end{array}$} & \multirow[t]{2}{*}{$\begin{array}{l}\text { Europe } \\
\left(n_{1}=33 I ; n_{2}=349\right)\end{array}$} & \multirow[t]{2}{*}{$\begin{array}{l}\text { US } \\
\left(n_{1}=100 ; n_{2}=100\right)\end{array}$} & \multicolumn{2}{|c|}{$\begin{array}{l}\text { Europe vs US } \\
(\text { ADHD) })^{\mathrm{a}}\end{array}$} \\
\hline & & & & & & Diff/OR & $P$-value \\
\hline \multicolumn{8}{|c|}{ Total provider visits, mean (SD) } \\
\hline ADHD & $12.5(13.8)^{*}$ & $7.2(10.5)^{*}$ & $7.8(10.5)^{*}$ & $9.0(1 \mathrm{I} .8)^{*}$ & $3.5(4.6)^{*}$ & $5.48^{\mathrm{b}}$ & $<0.001$ \\
\hline Non-ADHD & $4.3(9.1)$ & $2.4(3.7)$ & $2.8(5.0)$ & $3.1(6.1)$ & $1.8(3.9)$ & - & - \\
\hline \multicolumn{8}{|l|}{ ER visits, (\%) } \\
\hline ADHD & $30.0 *$ & $19.2^{*}$ & $44.6 *$ & $30.2^{*}$ & 21.0 & $1.21^{\mathrm{c}}$ & 0.519 \\
\hline Non-ADHD & 7.0 & 7.4 & 18.0 & 10.3 & 11.0 & - & - \\
\hline \multicolumn{8}{|c|}{ Hospitalizations, (\%) } \\
\hline ADHD & $32.0 *$ & $15.4^{*}$ & $33.7^{*}$ & $26.0^{*}$ & 13.0 & $1.58^{\mathrm{c}}$ & 0.195 \\
\hline Non-ADHD & 5.0 & 7.4 & 9.0 & 7.2 & 10.0 & - & - \\
\hline
\end{tabular}

Notes: *Significant differences between adults with and without ADHD in each country/region $(P<0.05)$; ${ }^{\text {athe }}$ figures above show the differences in health care resource utilization between adults with ADHD cohorts in Europe and the US, controlling for the interaction between ADHD status and region, as well as sociodemographics and comorbidity variables; 'differences in the least squares means. A difference of more than zero indicates more frequent visits to health care providers by adults with ADHD in Europe; 'differences in the least squares means, expressed in terms of OR. OR $>$ I indicates greater odds of using resources among ADHD cohorts in Europe. $n_{1}$ and $n_{2}$ represent the sample sizes of adults with and without ADHD, respectively, in each country.

Abbreviations: ADHD, attention-deficit/hyperactivity disorder; Diff, difference; ER, emergency room; OR, odds ratio; SD, standard deviation; vs, versus. 
relationships with co-workers $(\mathrm{OR}=1.74 ; P=0.049)$, and relationships with all others $(\mathrm{OR}=2.05 ; P=0.006)$.

Table 5 presents levels of health-related work productivity and activity impairments of those with and without ADHD in Europe and the US. Each of the WPAI productivity outcomes was consistently higher among adults with ADHD than among those without across Europe and the US. For example, adults with ADHD had a significantly higher percentage of overall work impairment (54.0\% [SD 31.1\%] versus 20.4\% [SD 27.4\%] in Europe and 32.2\% [SD 30.4\%] versus $13.9 \%$ [SD $25.2 \%$ ] in the US) and activity impairment (53.9\% [SD 26.5\%] versus 27.8\% [SD 30.2\%] in Europe and $41.9 \%$ [SD 31.8\%] versus $17.0 \%$ [SD 26.0\%] in the US) than those without ADHD. In addition, the level of overall work impairment among the adults with ADHD was greater in Europe than in the US. The percentage of overall work impairment among those with ADHD was higher in Europe by $17.42 \%$ (LS mean difference adjusted for the interaction between ADHD status and region, as well as other patient characteristics) $(P<0.001)$, whereas the percentage of daily activity impairments was similar between the two regions ( $\mathrm{LS}$ mean difference $=4.82, P=0.356$ ).

A similar pattern was also observed for health care resource use (Table 6). Adults with ADHD generally utilized more health care resources (ie, total number of health care provider visits, having ER visits, having hospital admissions) than those without ADHD across the countries. For example, the mean number of provider visits was approximately three times higher in adults with ADHD than in those without, both in Europe (9.0 [SD 11.8] versus 3.1 [SD 6.1]) and the US (3.5 [SD 4.6] versus 1.8 [SD 3.9]). In addition, the percentage of adults with ADHD who had ER visits or hospital admissions was at least three times greater than that of adults without ADHD in Europe $(30.2 \%$ versus $10.3 \%$ for ER visits and $26.0 \%$ versus $7.2 \%$ for hospital admissions). Although the percentages of ER visits and hospital admissions were also higher among adults with ADHD in the US, these were not significantly different from those among US adults without ADHD. The results of regression analyses confirmed that the total number of health care resources was likely to be greater among adults with ADHD in Europe than those in the US (LS difference in terms of $\mathrm{OR}=5.48, P<0.001)$. Although they also had more ER visits and hospital admissions than their US counterparts, the differences between the two were not significant.

\section{Discussion}

This study is one of few to quantitatively address the impact of ADHD on adults in Europe. The results of the international web-based study of adults reporting a current diagnosis of ADHD revealed a significant impact of the disorder on a range of outcomes, including social, family, and work relationships; comorbidities and health status; health-related work productivity impairment; and health care resource use within select geographies in Europe and the US. This study also delineates diagnostic and treatment pathways for adults with ADHD, highlighting similarities and differences across countries in Europe and the US.

\section{Burden of ADHD in adults}

A substantial proportion of respondents in Europe, particularly in Germany, consistently reported negative impacts of ADHD on their physical and mental health, career success, self-esteem, and various interpersonal relationships, including those with family, friends, and co-workers. In addition, they exhibited higher levels of work and activity impairments than adults without ADHD, as measured by the WPAI. Notably, the level of overall work impairment among adults with ADHD in Europe (54\%) was greater than that published for other conditions, such as rheumatoid arthritis with severe functional disability (47\% in the UK). ${ }^{21}$ Furthermore, adults with ADHD in Europe were more likely than those without to utilize health care resources. The mean number of provider visits and the percentage with ER visits and hospital admissions among adults with ADHD were all at least three times greater than those without the condition. Similarly, the percentage reporting at least one physiciandiagnosed comorbid condition (eg, depression, anxiety/ generalized anxiety disorder, other anxiety disorders, and sleep difficulties/insomnia) was also three-fold higher among adults with ADHD (71\% versus 25\%, respectively). This estimate of the high incidence of psychiatric comorbidities among adults with ADHD is consistent with findings from other studies, ${ }^{5}$ and emphasizes the need for therapists and medical professionals diagnosing and treating patients with ADHD to screen for other mental disorders in order to ensure optimal treatment. Although patterns exhibited in the US were similar, the magnitude of measured impacts of ADHD was generally greater in Europe, even after controlling for baseline characteristics of respondents across the two regions. This may result, in part, from the impact of less experience and lower levels of awareness, recognition of, and familiarity with adult ADHD in Europe relative to the US, ${ }^{10}$ possibly skewing diagnosis and treatment among ADHD populations in Europe toward the more severely impaired.

These findings are all directionally consistent with a wide array of previously published studies reporting on the impact 
of ADHD on adults. Numerous studies, mostly frequently conducted among individuals from the US, have identified and discussed the negative outcomes related to ADHD in adults in areas such as health, education, occupation, social functioning and relationships with others, antisocial behavior and criminal activities, work productivity impairments, and health care resource use..$^{4,10,15,22,23}$ For example, Barkley et $\mathrm{al}^{22}$ followed children with and without ADHD for at least 13 years and compared their adaptive functioning in adulthood in the US. They found that patients with ADHD were four times as likely to have contracted a sexually transmitted disease (16\% versus $4 \%$ ) and nine times (38\% versus $4 \%$ ) as likely to have become a parent by the end of the follow-up period as those without ADHD. They were also more likely to be unemployed or not in school (22\% versus $7 \%$ ) and fail to complete high school (32\% versus $0 \%) .{ }^{22}$ Similarly, Biederman et $\mathrm{a}^{23}$ reported that adults with ADHD in the US were less likely to obtain a college degree (19\% versus $26 \%$ ) and be employed ( $52 \%$ versus $72 \%$ ), but more likely to have been arrested (37\% versus $18 \%$ ) or divorced (28\% versus $15 \%$ ) than those without ADHD. Such negative impacts of ADHD can translate into a substantial economic burden, as shown in a recent US systematic review. ${ }^{15}$ Taken together, these findings suggest that more efforts should be made to provide early and effective treatments to respondents who would otherwise face unnecessary suffering, particularly in Europe where ADHD in adults is more often underdiagnosed and undertreated relative to the US. ${ }^{10}$

\section{Diagnostic and treatment pathways}

Although the findings demonstrated fairly similar diagnostic and treatment pathways among adults with ADHD across countries, some important differences emerged across European countries, as well as between Europe and the US, in patient experiences with seeking and receiving an initial diagnosis for, and the subsequent management of, their ADHD.

Varying levels of recognition of, and familiarity with, ADHD in adults among mental health care professionals, differing options available for the treatment and management of the condition, varying cultural stigmas associated with the disorder, and the nature and structure of health care delivery and payment may all play a role in shaping differing patient experiences and outcomes across the studied countries. ${ }^{3}$ For example, the greater prominence of PCPs in consultations leading to an initial diagnosis of ADHD in the UK than elsewhere in Europe likely reflects a greater role of PCPs as gatekeepers under the UK's National Health Service.
The study also revealed systematic differences in time to first diagnosis between Europe and the US. Slightly more than half of respondents in Europe (55\%) received a diagnosis within 6 months of their first visit to a health care professional due to ADHD symptoms, whereas a much larger majority in the US (90\%) received a diagnosis during this same time period. Also, fewer respondents in Europe were satisfied with the process leading to a diagnosis, particularly in Germany. More than half of European respondents (52\%) believed it took too long to get diagnosed with ADHD, and $40 \%$ agreed that their PCPs seemed hesitant to diagnose ADHD in adults (63\% and $47 \%$ for Germany, respectively). These rates were significantly higher than those reported in the US (39\% and $26 \%$, respectively). Notably, the percentages of respondents diagnosed with other mental health conditions prior to securing their diagnosis for ADHD were generally higher in Germany than elsewhere in Europe, particularly for conduct disorder, although the patterns among these conditions were fairly consistent across all countries. These findings are consistent with the view of the European Network Adult ADHD that there are still many health care professionals in Europe who are unsure of the diagnosis and the appropriate management of ADHD in adults. ${ }^{3}$

Treatment patterns also exhibited some notable differences between Europe and the US. Although a similar proportion of respondents in Europe (59\%) and the US (57\%) were currently treated with at least one ADHD medication, the types of medications prescribed/preferred differed, primarily in terms of variations in the types of stimulants prescribed. Methylphenidate was the most commonly prescribed medication in Europe, whereas amphetamine was the medication most commonly prescribed in the US. In addition, more respondents in Europe (68\%) than the US (54\%) reported having ever received nonpharmacological treatments such as cognitive behavioral therapy. These results are consistent with differences in available treatment options and treatment guidelines between the two regions. European guidelines ${ }^{2,24}$ tend to put more emphasis on a multimodal approach to the treatment of adults with ADHD, including both pharmacotherapy and psychosocial therapy; in the US, pharmacotherapy alone is often recommended as a first-line treatment option. Although psychostimulants are still most commonly prescribed for adults with ADHD in both regions, European guidelines ${ }^{2,25}$ have placed amphetamine as a third-line treatment option (behind methylphenidate and atomoxetine) due to a lack of efficacy data and safety concerns, most notably the greater potentials for drug abuse or misuse compared with methylphenidate. Apart from nonstimulant atomoxetine and 
an extended-release form of methylphenidate in Germany, no other medications have been approved for starting treatments in adults with ADHD in the European Union. ${ }^{26}$ In addition, European guidelines have not incorporated most recent clinical trial data on the use of nonstimulants, such as atomoxetine, nor amphetamines in adults with ADHD. ${ }^{26}$

\section{Limitations}

This study has several limitations that should be taken into account when interpreting the results. Those choosing to participate in the online survey may not have been fully representative of the ADHD and non-ADHD populations within their respective countries of residence. Identification of adults with and without ADHD, as well as demographics and clinical and behavioral information, were self-reported by survey respondents rather than obtained from clinical or administrative claims data. Self-reported information is subject to recall bias that may introduce additional error into observed associations. In addition, the more recent recognition and acceptance of ADHD's persistence into adulthood in Europe may have led to a more severely impaired ADHD respondent base in those regions than that from the US. Also, the country-specific sample sizes in this study were relatively small, possibly affecting the size and direction of observed relationships across the studied geographies. Furthermore, while statistical testing of primary study outcome measures was adjusted for demographics, sociodemographics, and baseline health status, the results may have been subject to confounding by regional imbalances in other respondent characteristics that were not collected in the survey. Additionally, some survey questions regarding the impact of ADHD on quality of life and obstacles encountered in obtaining an ADHD diagnosis were designed using five-point Likert-type agree-disagree response scales in conjunction with negatively worded statements, such as "ADHD has negatively impacted my self-esteem" and "it took too long to get diagnosed with ADHD". It has been hypothesized that there is a potential for bias towards agreement with questions presented in this fashion, which, if true, might bias results somewhat in these study areas. Finally, the accuracy of responses about events taking place at or around the time of initial diagnosis may be subject to greater potential error than questions regarding the current period or the recent past, thereby introducing an additional source of potential error to respondent evaluations of their diagnosis history.

\section{Conclusion}

Despite these limitations, this study, using cross-sectional web-based survey data, provides improved understanding of adults diagnosed with ADHD in Europe, where such information is currently limited. The results highlight a significant impact of ADHD in adults on a range of outcomes, including social, family, and work relationships, health-related work productivity impairment, and health care resource use, with unmet needs generally greater among European study participants than those from the US. Efforts should continue to promote the delivery of early and effective treatments to European adults with ADHD, who would otherwise face unnecessary suffering.

\section{Disclosure}

Stephen L Able and Virginia Haynes are employees of Eli Lilly and Company. Jihyung Hong is a consultant for Eli Lilly and Company. Eli Lilly and Company contracted with Kantar Health for the purchase of data from the NHWS database and for services associated with the programming, conducting, and processing of data from custom web-based surveys in support of this study. The authors have no other conflicts of interest in this work.

\section{References}

1. American Psychiatric Association. Diagnostic and Statistical Manual of Mental Disorders, 5th Edition: DSM-5. Washington, DC: American Psychiatric Association; 2013.

2. National Institute for Health and Clinical Excellence. NICE Clinical Guideline 72: Attention Deficit Hyperactivity Disorder. Diagnosis and Management of ADHD in Children, Young People and Adults. London: National Institute for Health and Clinical Excellence; 2008.

3. Kooij SJ, Bejerot S, Blackwell A, et al. European consensus statement on diagnosis and treatment of adult ADHD: The European Network Adult ADHD. BMC Psychiatry. 2010;10:67.

4. Faraone SV, Biederman J, Mick E. The age-dependent decline of attention deficit hyperactivity disorder: a meta-analysis of follow-up studies. Psychol Med. 2006;36(2):159-165.

5. Fayyad J, De Graaf R, Kessler R, et al. Cross-national prevalence and correlates of adult attention-deficit hyperactivity disorder. $\mathrm{Br} J$ Psychiatry. 2007;190:402-409.

6. Rösler M, Casas M, Konofal E, Buitelaar J. Attention deficit hyperactivity disorder in adults. World J Biol Psychiatry. 2010;11(5):684-698.

7. Das D, Cherbuin N, Butterworth P, Anstey KJ, Easteal S. A populationbased study of attention deficit/hyperactivity disorder symptoms and associated impairment in middle-aged adults. PLoS One. 2012;7(2):e31500.

8. Biederman J, Faraone SV. The effects of attention-deficit/hyperactivity disorder on employment and household income. MedGenMed. 2006;8(3):12.

9. Murphy K, Barkley RA. Attention deficit hyperactivity disorder adults: comorbidities and adaptive impairments. Compr Psychiatry. 1996;37(6):393-401.

10. Asherson P, Akehurst R, Kooij JJ, et al. Under diagnosis of adult ADHD: cultural influences and societal burden. J Atten Disord. 2012; 16(Suppl 5):20S-38S

11. Secnik K, Swensen A, Lage MJ. Comorbidities and costs of adult respondents diagnosed with attention-deficit hyperactivity disorder. Pharmacoeconomics. 2005;23(1):93-102.

12. Biederman J, Faraone SV, Spencer T, Wilens T, Mick E, Lapey KA. Gender differences in a sample of adults with attention deficit hyperactivity disorder. Psychiatry Res. 1994;53(1):13-29. 
13. Klassen LJ, Bilkey TS, Katzman MA, Chokka P. Comorbid attention deficit/hyperactivity disorder and substance use disorder: treatment considerations. Curr Drug Abuse Rev. 2012;5(3):190-198.

14. Minkoff NB. ADHD in managed care: an assessment of the burden of illness and proposed initiatives to improve outcomes. Am J Manag Care. 2009;15(Suppl 5):S151-S159.

15. Doshi JA, Hodgkins P, Kahle J, et al. Economic impact of childhood and adult attention-deficit/hyperactivity disorder in the United States. J Am Acad Child Adolesc Psychiatry. 2012;51(10):990-1002. e2.

16. Brod M, Pohlman B, Lasser R, Hodgkins P. Comparison of the burden of illness for adults with ADHD across seven countries: a qualitative study. Health Qual Life Outcomes. 2012;10:47.

17. Kantar Health [homepage on the Internet]. New York, NY: Kantar Health; 2013. Available from: http://www.kantarhealth.com/. Accessed January 17, 2014.

18. Reilly MC, Zbrozek AS, Dukes EM. The validity and reproducibility of a work productivity and activity impairment instrument. Pharmacoeconomics. 1993;4(5):353-365

19. Reilly MC, Bracco A, Ricci JF, Santoro J, Stevens T. The validity and accuracy of the Work Productivity and Activity Impairment questionnaire - irritable bowel syndrome version (WPAI:IBS). Aliment Pharmacol Ther. 2004;20(4):459-467.

20. Reilly MC, Gerlier L, Brabant Y, Brown M. Validity, reliability, and responsiveness of the work productivity and activity impairment questionnaire in Crohn's disease. Clin Ther. 2008;30(2):393-404.
21. Zhang W, Bansback N, Boonen A, Young A, Singh A, Anis AH. Validity of the work productivity and activity impairment questionnaire - general health version in respondents with rheumatoid arthritis. Arthritis Res Ther. 2010;12(5):R177.

22. Barkley RA, Fischer M, Smallish L, Fletcher K. Young adult outcome of hyperactive children: adaptive functioning in major life activities. J Am Acad Child Adolesc Psychiatry. 2006;45(2):192-202.

23. Biederman J, Faraone SV, Spencer TJ, Mick E, Monuteaux MC, Aleardi M. Functional impairments in adults with self-reports of diagnosed ADHD a controlled study of 1001 adults in the community. J Clin Psychiatry. 2006;67(4):524-540.

24. Taylor E, Döpfner M, Sergeant J, et al. European clinical guidelines for hyperkinetic disorder - first upgrade. Eur Child Adolesc Psychiatry. 2004;13(Suppl 1):I7-I30.

25. King S, Griffin S, Hodges Z, et al. A systematic review and economic model of the effectiveness and cost-effectiveness of methylphenidate, dexamfetamine and atomoxetine for the treatment of attention deficit hyperactivity disorder in children and adolescents. Health Technol Assess. 2006;10(23):iii-iv, xiii-146.

26. Ramos-Quiroga JA, Montoya A, Kutzelnigg A, Deberdt W, Sobanski E Attention deficit hyperactivity disorder in the European adult population: prevalence, disease awareness, and treatment guidelines. Curr Med Res Opin. 2013;29(9):1093-1104
Pragmatic and Observational Research

\section{Publish your work in this journal}

Pragmatic and Observational Research is an international, peer-reviewed, open access journal that publishes data from studies designed to reflect more closely medical interventions in real-world clinical practice compared with classical randomized controlled trials (RCTs). The manuscript management system is completely online and includes a very quick and fair peer-review

\section{Dovepress}

system. Visit http://www.dovepress.com/testimonials.php to read real quotes from published authors 